3

4 Lieselot Balduyck $^{1^{*}}$, Sebastiaan Bijttebier ${ }^{2,3}$, Charlotte Bruneel ${ }^{1}$, Griet Jacobs ${ }^{2}$, Stefan

5

6

7

$8 \quad{ }^{1}$ KU Leuven Kulak, Research Unit Food \& Lipids, E. Sabbelaan 53, 8500 Kortrijk, 9 Belgium

(1) Belgium

Leuven Food Science and Nutrition Research Centre (LFoRCe), KU Leuven, Kasteelpark Arenberg 20, 3001 Leuven, Belgium

2 Flemish Institute for Technological Research (VITO), Business Unit Separation and Conversion Technology (SCT), Boeretang 200, 2400 Mol, Belgium

${ }^{3}$ University of Antwerp, Natural Products \& Food Research and Analysis (NatuRA), Universiteitsplein 1, 2610 Antwerp, Belgium

${ }^{4}$ Research Group Molecular Odor Chemistry, KU Leuven Campus Ghent, Technology Campus, Gebroeders De Smetstraat 1, B-9000 Ghent, Belgium

${ }^{5}$ KU Leuven Kulak, Laboratory Aquatic Biology, E. Sabbelaan 53, 8500 Kortrijk, Belgium 19

${ }^{*}$ Corresponding author:

Email: lieselot.balduyck@kuleuven.be

Tel: +32 56246026

\section{Lipolysis in T-Isochrysis lutea during wet storage at different} temperatures 
Previously, it has been observed that lipolysis occurring during (even short term) wet storage of microalgal biomass causes high free fatty acid (FFA) concentrations in the biomass. These FFA have a negative impact for different applications of microalgal lipids, e.g. downstream processing problems in biodiesel production, off-flavors and loss of nutritional value for food applications. However, it is not clear which factors influence lipolysis in microalgal biomass and which lipid class are more susceptible to lipolysis. In this study, wet biomass of $T$-Isochrysis lutea was stored at $20^{\circ} \mathrm{C}, 4^{\circ} \mathrm{C}$ and $-20^{\circ} \mathrm{C}$ during 3 weeks. The extent of lipolysis was followed by analyzing the lipid classes distribution by ultrahigh-performance liquid chromatography-accurate mass mass spectrometry (UHPLC-amMS) and the FFA content. It was observed that FFA were formed very rapidly during post-harvest storage of wet biomass at $20^{\circ} \mathrm{C}$ and $4^{\circ} \mathrm{C}$, the rate of this process being faster at $20^{\circ} \mathrm{C}$ than at $4^{\circ} \mathrm{C}$, while almost no lipolysis was observed at $-20^{\circ} \mathrm{C}$. However, the FFA content levelled off after several days of storage because FFA reacted with alcohols to form fatty acyl esters.

Keywords

stability

microalgae

lipids

free fatty acids

lipolysis

lipase 
Microalgae are an extremely diverse group of unicellular, photosynthetic microorganisms, found in marine, brackish or freshwater environments. Microalgal cells consist mainly of carbohydrates (4-50\%), lipids (10-50\%) and proteins (30-60\%), which all can be used for several applications in different markets (Li et al., 2015; Koller et al., 2014; Xu et al., 2011; Spolaore et al., 2006). Relative amounts of these compounds strongly depend on the species and the nutritional and environmental factors during cultivation (Koller et al., 2014; Spolaore et al., 2006).

The lipid part of microalgae can have applications in different industries. First, microalgal lipids can have a role in the supply of biodiesel. Hereto, triacylglycerols are converted to methyl esters by a transesterification reaction catalyzed by acid or alkali catalysts or by lipase enzymes (Navarro López et al., 2015). In addition, some marine species (e.g. Nannochloropsis, T-Isochrysis) contain substantial amounts of long chain omega-3 polyunsaturated fatty acids ( $\omega$-3 LC-PUFA), which have been demonstrated to possess health-promoting effects, particularly eicosapentaenoic acid (EPA; C20:5n-3) and docosahexaenoic acid (DHA; C22:6n-3) (Calder, 2014). These are promising ingredients

67 for use in among others functional foods, nutraceuticals, pharmaceuticals and cosmetics (Borowitzka, 2013; Spolaore et al., 2006).

Production of microalgal biomass and products derived thereof is performed in several sequential steps. For each step different techniques are possible with their corresponding efficiency and quality implications. In a first step, microalgae are cultivated in open ponds or photobioreactors during a few days to weeks, after which 
the microalgal cells are harvested. In most cases, this occurs by centrifugation, but also alternative, less energy consuming techniques, e.g. flocculation and filtration have been proposed. Harvesting yields a wet, microalgal paste which typically contains 5 to $25 \%$ of dry matter, depending on the number and type of harvesting techniques used (Mata et al., 2010). In a next step, this paste can be dried to obtain a dry microalgal powder.

To obtain stable products of good quality, storage of microalgae as dried microalgal powder ('dry storage') is preferred. However, a (short) period of storage of microalgal paste after harvesting ('wet storage') is often inevitable in practice. Moreover, life cycle assessment studies have shown that the drying process accounts for a high percentage of the total energy consumption in the production process (e.g. Slegers et al., 2014; Xu et al., 2011). Therefore, during the last years, numerous studies have explored the potential of oil extraction from wet biomass, as this would avoid the energy required for drying (Tanzi et al., 2013; Xu et al., 2011). An attractive option for biodiesel production is direct transesterification of the lipids in the wet biomass (Wahlen et al., 2011). However, for both direct extraction and direct transesterification on wet biomass, the yield of these processes has been found to be strongly negatively influenced by the moisture content (Tanzi et al., 2013; Wahlen et al., 2011). Moreover, only comparisons of lipid yields have been made. Investigations focusing on quality implications have hardly been performed.

During storage of wet biomass, endogenous hydrolytic enzymes present in the biomass may cause lipolysis, being the dissociation of free fatty acids (FFA) from the lipids. These 
process, saponification reactions can take place between FFA and alkali catalysts if the oil contains more than $0.5 \%$ FFA, leading to a reduced amount of catalyst present and several downstream separation problems (Navarro Lopez et al., 2015). In addition, the presence of FFA causes rancid flavors, which are not desirable in food applications. Furthermore, FFA are known to have a pro-oxidative effect (e.g. Aubourg, 2001) and are also more easily oxidized by lipoxygenase enzymes than fatty acids in the esterified form (Frankel, 2005). As oxidation products are also known to have several deleterious effects (e.g. off-flavors, decrease of nutritional value, negative impact on biodiesel production process), this once again shows the importance of avoiding lipolysis (Gordon, 2001).

In literature, several recent studies have indicated that lipolysis may be a serious problem during storage of wet microalgal biomass. Firstly, Ryckebosch et al. (2011a) reported that pronounced lipolysis occurred after two days of wet storage at $4^{\circ} \mathrm{C}$ of centrifuged microalgal paste of Phaeodactylum tricornutum, while this was not the case when the microalgae were dried immediately. This led to significant lipid losses in the biomass. Chen et al. (2012) also observed a fast increase in FFA content from trace proportions to $62 \%$ FFA in the oil during 4 days of wet storage of Scenedesmus sp. paste (75\% moisture) at $4^{\circ} \mathrm{C}$. At higher storage temperatures, lipolysis reactions occurred even faster, with $70.3 \% \mathrm{FFA}$ in the oil after 1 day at $25^{\circ} \mathrm{C}$ and $66.8 \%$ after 1 day at $37^{\circ} \mathrm{C}$. These studies proved that even short-term storage of wet biomass can possibly induce substantial lipolysis problems. The presence of lipase activity has already been reported in Dunaliella salina (Cho and Thompson, 1986), Phaeodactylum tricornutum (Barka et al., 2016) and Spirulina platensis (Demir and Tükel, 2010). In Isochrysis galbana, Godet et al. (2010, 2012) and Kerviel et al. (2014) isolated and characterized genes encoding 
118 for carboxylesterase and/or lipase-like enzymes for potential use in metabolic 119 engineering to enhance lipid yields in microalgae.

120 Despite the importance of lipolysis for both biodiesel and food applications, the

121 occurrence of this process during wet storage of microalgal biomass has, to the best of our knowledge, not yet been investigated thoroughly. Underlying processes leading to lipolysis, species dependency and enzyme specificity are thus not elucidated yet. The aim of this study was to understand the time and temperature dependence of lipolysis and FFA formation and accumulation during both short and long term storage of wet microalgal biomass. For this study, T-Isochrysis lutea was selected, as this species contains high amounts of lipids, including $\omega-3$ LC-PUFA, and is consequently a promising source of lipids for both biodiesel and food applications (Li et al., 2015). As microalgae contain different lipid classes (e.g. triacylglycerols, phospholipids, glycolipids), we also wanted to investigate whether lipolysis affects all lipid classes to the same degree. Therefore, a detailed separation in lipid classes by ultrahigh-performance liquid chromatography- accurate mass mass spectrometry (UHPLC-amMS) was performed at different times during storage of the biomass at different temperatures.

\section{Materials and methods}

Solvents used for lipid extractions, FFA determinations and UHPLC-amMS analyses (chloroform, methanol, dichloromethane and ethyl acetate) were HPLC grade and were obtained from Carl Roth (Karlsruhe, Germany) or Biosolve (Valkenswaard, The Netherlands). For UHPLC-amMS analyses, ultrapure water with a resistivity of 18.2 $\mathrm{M} \Omega \cdot \mathrm{cm}$ at $25^{\circ} \mathrm{C}$ was generated with a Millipore system. 
142 T-Isochrysis lutea, formerly named Isochrysis sp. (CCAP 927/14; Culture Collection of 143 Algae and Protozoa, Oban, United Kingdom), was cultured in Wright's Cryptophyte (WC) 144 medium (Guillard and Lorenzen, 1972) to which artificial sea salt (Homarsel, Zoutman Industries, Roeselare, Belgium) was added in a concentration of $30 \mathrm{~g} / \mathrm{L}$. The cultivation was carried out in $30 \mathrm{~L}$ photobioreactors incubated at controlled temperature $\left(20^{\circ} \mathrm{C}\right)$. The reactors were irradiated with daylight fluorescent tubes in a cycle of 16 light hours and 8 dark hours and were aerated with filtered air. The $\mathrm{pH}$ of the medium was adjusted to 8-8.1 and an inoculum of microalgae was added. During cultivation, the $\mathrm{pH}$ was controlled at $8.5( \pm 0.2)$ by addition of $\mathrm{CO}_{2}$ using a pH stat system. Growth of the microalgae was monitored by measuring the optical density at $750 \mathrm{~nm}$.

Harvesting was carried out in the early stationary phase after 10 days of cultivation using a lamella centrifuge (4000 g), followed by a further concentration by centrifugation (9500 g, Sorvall RC-5B, Du Pont Instruments).

The harvested wet microalgal paste $(7.8 \pm 0.5 \%$ dry matter as determined by drying the wet paste to constant weight in an oven at $100^{\circ} \mathrm{C}$ ) was immediately stored in $50 \mathrm{~mL}$ falcon tubes in the dark at 3 different temperatures $\left(20^{\circ} \mathrm{C}, 4^{\circ} \mathrm{C}\right.$ and $\left.-20^{\circ} \mathrm{C}\right)$ during a period of 3 weeks. Samples were collected at 8 different time points $(0,0.5,1,2,3,7,14$ and 21 days) and immediately freeze dried and stored at $-80^{\circ} \mathrm{C}$ until analyses. Preliminary experiments have shown that microalgal biomass remains stable in these conditions (detailed results not shown). 


\subsubsection{Lipid extraction from microalgal biomass}

Total lipids of all collected samples were extracted with chloroform/methanol $(1: 1 \mathrm{v} / \mathrm{v})$ according to the method described in Ryckebosch et al. (2011b) and determined gravimetrically. Briefly, $4 \mathrm{~mL}$ methanol, $2 \mathrm{~mL}$ chloroform and $0.4 \mathrm{~mL}$ water were added to $100 \mathrm{mg}$ of lyophilized microalgae. In case of extraction for FFA determination (described in 2.3.2), 5 mg of lauric acid (C12:0) (Nu-Check Prep, Elysian, USA), dissolved in chloroform, was added as an internal standard. After homogenizing, $2 \mathrm{~mL}$ chloroform and $2 \mathrm{~mL}$ water were added. The samples were homogenized again and subsequently centrifuged at $750 \mathrm{~g}$ for 10 minutes. The upper (water) layer was removed, while the lower layer was transferred to another tube. The remaining pellet was re-extracted with $4 \mathrm{~mL}$ of chloroform/methanol (1:1) and centrifuged again at $750 \mathrm{~g}$ for 10 minutes. The supernatant was transferred to the same tube as before while the pellet was extracted again according to the same procedure. The combined solvent layers were filtered through a sodium sulphate layer to remove the remaining water. The lipid content was measured gravimetrically after evaporating the solvents. All extractions were done in triplicate.

\subsubsection{Determination of FFA content}

The FFA content was determined by derivatization of the FFA in the lipid extract to diethylamide derivatives according to Ryckebosch et al. (2011a), based on Kangani et al. (2008). Therefore, $10 \mathrm{mg}$ of the extracted lipids was dissolved in $1 \mathrm{~mL}$ dichloromethane. After addition of $10 \mu \mathrm{l}$ diisopropylethylamine and $30 \mu \mathrm{l}$ diethylamine (Sigma-Aldrich, 
Bornem, Belgium), the solution was cooled to $0^{\circ} \mathrm{C} .20 \mu \mathrm{l}$ of bis(2methoxyethyl)aminosulfur trifluoride (Sigma-Aldrich, Bornem, Belgium) was added dropwise. After homogenizing, the mixture was kept at $0^{\circ} \mathrm{C}$ for 5 minutes, subsequently warmed to room temperature and kept there for 15 minutes. Water $(2 \mathrm{~mL})$ and hexane $(4 \mathrm{~mL})$ were added, after which the solution was homogenized and centrifuged at $750 \mathrm{~g}$ for 10 minutes.

The upper layer, containing the amide derivatives, was analyzed by gas chromatography with cold on-column injection and FID detection (Trace GC, Interscience, Louvain-laNeuve, Belgium). An EC Wax column (length 30 m, ID 0.32 mm, film $0.25 \mu \mathrm{m}$; Grace, Lokeren, Belgium) was used with the following time-temperature program: 100 to 160

\section{UHPLC- amMS analysis}

201

A standard stock solution of trans- $\beta$-apo-8'-carotenal (Sigma-Aldrich, Bornem, Belgium) was prepared at a concentration of approximately $3000 \mu \mathrm{g} / \mathrm{mL}$ in dichloromethane, to 203 which $0.1 \%$ BHT was added (Sigma-Aldrich, Bornem, Belgium) and was used as an internal standard. of all collected samples were analyzed with UHPLC- amMS. After evaporating the 
solvent, approximately $4 \mathrm{mg}$ of the dry extract was redissolved in $0.5 \mathrm{~mL} 1: 1$ chloroform:methanol + internal standard (trans- $\beta$-apo-8'-carotenal at a concentration of approximately $15 \mu \mathrm{g} / \mathrm{mL}$ ) and injected with a CTC PAL autosampler (CTC Analytics, Zwingen, Switzerland) on a Waters Acquity UPLC BEH Shield RP C18 column (2.1 mm x $100 \mathrm{~mm}, 1.8 \mu \mathrm{m}$; Waters, Milford, MA). Analytes were thermostatically $\left(50^{\circ} \mathrm{C}\right)$ eluted at a flow rate of $0.5 \mathrm{~mL} / \mathrm{min}$ with an Accela' ${ }^{\mathrm{TM}}$ quaternary solvent manager and a 'Hot Pocket' column oven (Thermo Fisher Scientific, Bremen, Germany). The mobile phase solvents consisted of water $+20 \mathrm{mM}$ ammonium acetate $(A)$, methanol $+20 \mathrm{mM}$ ammonium acetate (B) and ethyl acetate (C). The gradient was set as follows (min/\%A/\%B): $\quad 0.00 / 50 / 50, \quad 20.00 / 0 / 100, \quad 25.00 / 0 / 20, \quad 27.00 / 0 / 20,28.00 / 50 / 50$, $30.00 / 50 / 50$. The LC-system was hyphenated to an orbitrap mass spectrometer ( $Q$ Exactive; Thermo Fisher Scientific, Bremen, Germany). Full MS scan data were acquired in HESI positive and negative mode within one analysis with a mass-to-charge range ( $\mathrm{m} / \mathrm{z}$-range) of 90-1350 and resolving power set at 70,000 Full Width at Half Maximum (FWHM). Data were also recorded using selective ion fragmentation (data dependent $\mathrm{MS}^{2}$ or $\mathrm{ddMS}^{2}$ ) in positive and negative mode (one analysis per mode) to obtain additional structural information (resolving power set at 17,500 FWHM, collision energy $30 \mathrm{~V}$, isolation window: $4 \mathrm{~m} / \mathrm{z}$ ). Each sample was analyzed in duplicate.

\section{Data handling}

A hybrid quadrupole-orbital trap MS-analyser was used for lipid identification. This enables selective ion fragmentation, a functionality that contributes significantly to compound identification by generating clean product ion spectra. Selective ion 
fragmentation is particularly useful for associating product ions with precursor ions during coelution of multiple lipids, as is often the case in complex extracts. The most abundant precursor ions were selected for lipid quantification. The total area per lipid class was obtained by summation of all areas of different components (e.g. different fatty acyl chain) within this lipid class. This area was corrected both for the internal standard (trans- $\beta$-apo- 8 '-carotenal) and for the sample weight. Because no response factors were available for all lipid classes, no relative composition of the lipid fraction could be calculated. Instead, arbitrary relative areas were calculated by dividing the corrected areas by the sum of all corrected areas within a sample. Within each lipid class, the highest value was set to 100 , thus obtaining relative abundances varying from 0 to 100 in each lipid class. These relative areas do not represent percentages within a lipid sample, but rather the evolution of the amount of each lipid class during the storage period.

\subsection{Analysis of volatile compounds in wet biomass by Headspace-Solid Phase} Microextraction - Gas Chromatography - Mass Spectrometry (HS-SPME-GCMS)

To investigate the presence of alcohols, the wet samples were analyzed by GC-MS. A fully automated sample preparation unit (MultiPurpose Sampler ${ }^{\circledR}$ or MPS ${ }^{\circledR}, \mathrm{GERSTEL}^{\circledR}$, Mülheim an der Rur, Germany), combined with a 6890/5973 GC-MS system (Agilent Technologies ${ }^{\circledR}$, Palo Alto, CA) was used for compound separation and identification. This method is based on a previous study (Vandamme et al., 2015). Briefly, about $100 \mathrm{mg}$ of the wet biomass was hermetically sealed in $20 \mathrm{~mL}$ vials and incubated for 30 minutes at 
$60^{\circ} \mathrm{C}$ using agitation. Extraction was done using a $75 \mu \mathrm{m}$ CAR/PDMS fiber type for 30 minutes. The loaded SPME-fiber was thermally extracted in the GC-injector. Helium was used as a carrier gas ( $1 \mathrm{~mL} / \mathrm{min})$. Injector and transfer lines were maintained at $250^{\circ} \mathrm{C}$ and $280^{\circ} \mathrm{C}$, respectively. The total ion current $(70 \mathrm{eV})$ was recorded in the mass range from 40 to 230 amu (scan mode) and a run time of $52 \mathrm{~min}$. For GC-MS profiling, a ZBWAXplus column, $30 \mathrm{~m} \times 0.25 \mathrm{~mm}$ I.D., $0.25 \mu \mathrm{m}$ film thickness (Phenomenex ${ }^{\circledR}$, Utrecht, Netherlands) was used and programmed: $40^{\circ} \mathrm{C}(5 \mathrm{~min})$ to $250^{\circ} \mathrm{C}$ at $5{ }^{\circ} \mathrm{C} / \mathrm{min}$, held for 5 min. Identification of volatiles was performed by comparison with the mass spectra of the Wiley ${ }^{\circledR} 275$ library.

\subsection{Evolution of lipid content during wet storage}

The total lipid content (on dry basis) was measured in the start biomass (before storage, i.e. day 0) and in all collected biomass samples that were stored at three storage temperatures $\left(20^{\circ} \mathrm{C}, 4^{\circ} \mathrm{C}\right.$ and $\left.-20^{\circ} \mathrm{C}\right)$ for three weeks. The start biomass of $T$-Isochrysis had a total lipid content of $31.3 \pm 0.8 \%$. This is in agreement with values found in literature for Isochrysis sp., varying between 18 and 34\% depending on cultivation conditions such as medium, growth phase and light intensity (Huerlimann et al., 2010; Zhu et al., 1997). Although some significant differences could be detected, no clear increase or decrease of the lipid content as function of time was observed for any of the storage temperatures (Table 1 ). 
Table 1: Evolution of the total lipid content on dry basis ( $\mathrm{g} / 100 \mathrm{~g}$ biomass) during storage of wet microalgal paste at $20^{\circ} \mathrm{C}, 4^{\circ} \mathrm{C}$ and $-20^{\circ} \mathrm{C}$.

storage time Total lipid content ( $\mathrm{g} / 100 \mathrm{~g}$ biomass)

\begin{tabular}{llll}
\hline & $20^{\circ} \mathrm{C}$ & $4^{\circ} \mathrm{C}$ & $-20^{\circ} \mathrm{C}$ \\
\hline directly after harvesting & $31.3 \pm 0.8^{\mathrm{ab}}$ & $31.3 \pm 0.8^{\mathrm{ab}}$ & $31.3 \pm 0.8^{\mathrm{a}}$ \\
12 hours & $29.5 \pm 0.4^{\mathrm{abcd}}$ & $29.8 \pm 1.1^{\mathrm{abc}}$ & $32.0 \pm 0.9^{\mathrm{a}}$ \\
1 day & $30.2 \pm 0.4^{\mathrm{abc}}$ & $29.3 \pm 1.6^{\mathrm{bc}}$ & $30.8 \pm 0.3^{\mathrm{ab}}$ \\
2 days & $27.1 \pm 1.7^{\mathrm{abc}}$ & $29.9 \pm 1.3^{\mathrm{abc}}$ & $31.0 \pm 0.6^{\mathrm{ab}}$ \\
3 days & $29.2 \pm 2.1^{\mathrm{bcd}}$ & $30.0 \pm 1.0^{\mathrm{abc}}$ & $31.2 \pm 1.0^{\mathrm{a}}$ \\
7 days & $28.1 \pm 1.0^{\mathrm{cd}}$ & $27.8 \pm 0.9^{\mathrm{c}}$ & $29.3 \pm 0.4^{\mathrm{bc}}$ \\
2 weeks & $29.6 \pm 0.6^{\mathrm{abcd}}$ & $30.2 \pm 1.1^{\mathrm{ab}}$ & $31.5 \pm 1.1^{\mathrm{a}}$ \\
3 weeks & $31.9 \pm 1.6^{\mathrm{a}}$ & $32.0 \pm 1.5^{\mathrm{a}}$ & $27.7 \pm 1.9^{\mathrm{c}}$
\end{tabular}

275

abcd Different superscripts indicate significantly differing values per storage temperature

277 ( $p \leq 0.05$, Tukey test).

3.2. Evolution of FFA content during wet storage

279 The FFA content in the lipid fraction of all samples was determined and the results are presented in Figure 1.

Figure 1: Evolution of the FFA content (\% of total lipids) during 3 weeks of storage of wet biomass ( $8 \%$ dry matter) of T-Isochrysis lutea at $20^{\circ} \mathrm{C}(\bullet), 4^{\circ} \mathrm{C}(\mathrm{O})$ and $-20^{\circ} \mathrm{C}(\nabla)$. 


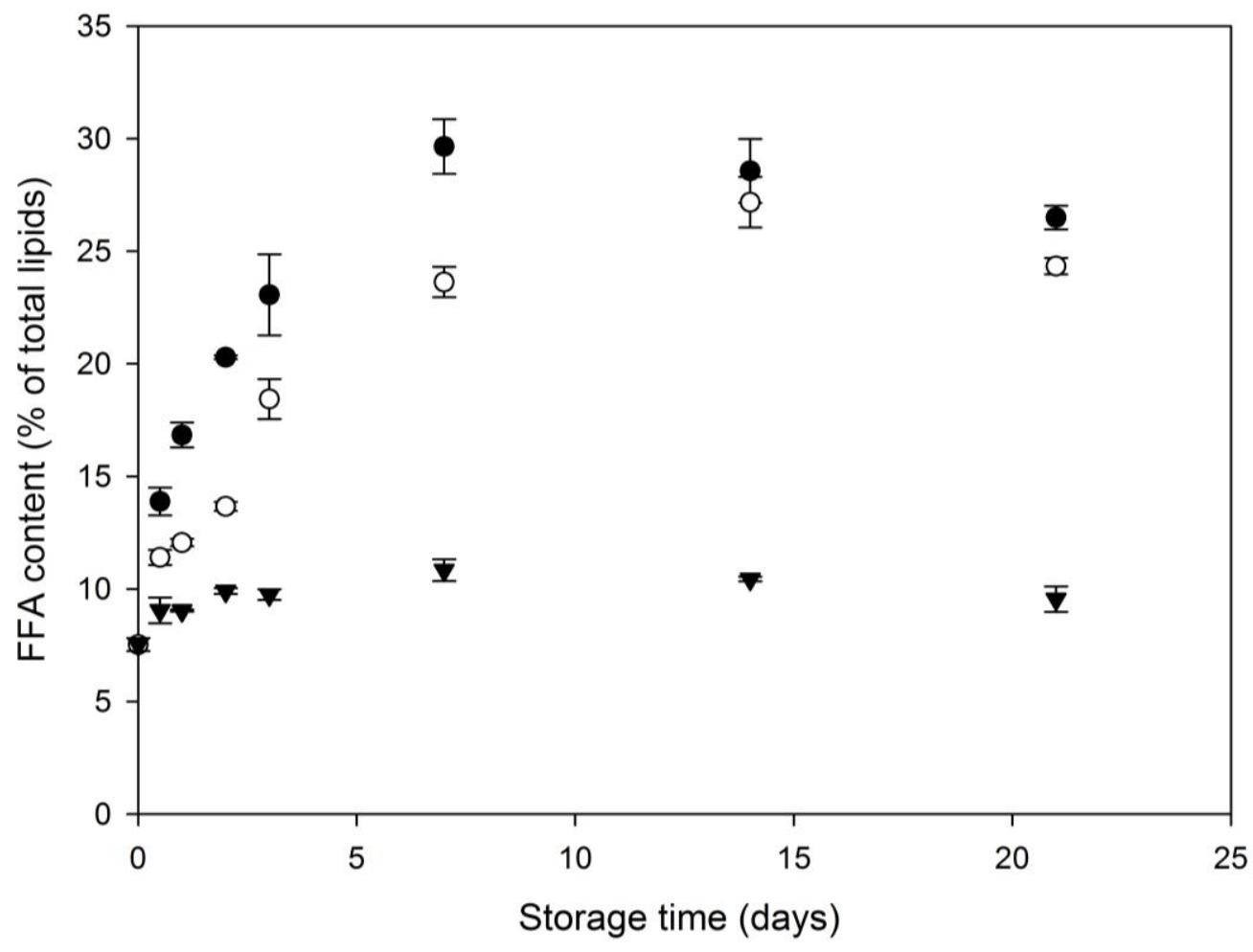

During storage at $-20^{\circ} \mathrm{C}$, almost no lipolysis was observed. Although the FFA content was significantly higher after one day storage than in the start biomass, the FFA content remained approximately stable during 3 weeks of storage. When biomass was stored at $4^{\circ} \mathrm{C}$, the FFA content increased very rapidly during the first days of storage. In the biomass stored at $20^{\circ} \mathrm{C}$, this increase occurred even faster. This demonstrates a strong temperature dependency of lipolysis reactions. These results are also in agreement with 291 the study of Chen et al. (2012), in which the increase in FFA content during 1 day of wet storage of Scenedesmus sp. was highest between $25^{\circ} \mathrm{C}$ and $37^{\circ} \mathrm{C}$. When stored at $4^{\circ} \mathrm{C}$, a significant increase was also observed, but to a lesser extent, while there were no FFA 294 formed during storage at $-20^{\circ} \mathrm{C}$ and $-80^{\circ} \mathrm{C}$. Ryckebosch et al. (2011a) also found a 
As the cultivation of T-Isochrysis lutea was not conducted axenically, an additional experiment was performed to ensure that the observed lipolysis reactions were caused by endogenous enzymes and not by bacterial lipases. Therefore, a mixture of 5 antibiotics (250 $\mathrm{gg} \mathrm{mL}^{-1}$ ampicillin, $50 \mu \mathrm{g} \mathrm{m}^{-1}$ gentamycin, $100 \mu \mathrm{g} \mathrm{mL}^{-1}$ kanamycin, 500 $\mu \mathrm{g} \mathrm{mL} \mathrm{L}^{-1}$ neomycin, $50 \mu \mathrm{g} \mathrm{mL} \mathrm{L}^{-1}$ streptomycin) was added to the wet biomass of $T$ Isochrysis lutea after harvesting and subsequently stored at $4^{\circ} \mathrm{C}$ during 2 weeks. This method was adopted from Cho et al. (2002), in which it was shown that this antibiotic mixture inhibited bacterial growth in a contaminated culture of Isochrysis galbana. The FFA content was followed at different time intervals and compared to the control biomass, to which no antibiotics were added. It was observed that the FFA content was not significantly different between the biomass treated with antibiotics and the control biomass (detailed results not shown). It could thus be concluded that the lipolysis observed in T-Isochrysis originated from endogenous hydrolytic enzymes present in microalgal biomass.

\subsubsection{Lipolysis induction mechanism}

313 A very high FFA content $(7.5 \pm 0.3 \%$ of total lipids) was already observed in the biomass

314 immediately after harvesting. To clarify whether these FFA were already present in the biomass prior to harvesting or were formed during harvesting, this value was compared to the FFA content of a smaller sample of T-Isochrysis biomass that could be harvested 
more rapidly and subsequently freeze dried immediately. In this sample, the FFA content was $2.50 \pm 0.04 \%$ of total lipids, which is significantly lower, but still not negligible. However, it is unlikely that high amounts of FFA are present in intact, living cells. FFA are possibly interfering with enzyme functions and inhibit electron transfer. Moreover, the higher sensitivity of FFA to oxidation causes the production of degradation products that are toxic for cells (Berge et al., 1995). Therefore, it was hypothesized that the FFA observed in freshly harvested biomass were produced during and immediately after harvesting. The shorter harvesting protocol caused a lower FFA content in the start biomass but was not able to completely avoid lipolysis.

The rapid formation of FFA in T-Isochrysis biomass may be caused by an innate defense mechanism against grazers. When diatoms are consumed by grazers and the cell integrity is compromised, lipase enzymes are activated and these rapidly form FFA, which are then further converted by lipoxygenase and hydroperoxide lyase enzymes into several oxylipin compounds (e.g. aldehydes), which are toxic for several types of grazers (Cosse et al., 2008; Pohnert, 2002). It is suggested that in T-Isochrysis cells, which have a weak cell wall consisting of mannose (Espinosa et al., 2010) or even do not have the first hours or days of wet storage. 
A remarkable observation in Figure 1 is the level off effect that was observed in the FFA content starting after 7 days of wet storage at $20^{\circ} \mathrm{C}$ and after 2 weeks at $4^{\circ} \mathrm{C}$. Several hypotheses can possibly explain this effect.

Firstly, it is possible that conditions in the harvested, microalgal paste are evolving towards unfavorable for enzymatic reactions. The most important factors determining enzymatic reactions are temperature and $\mathrm{pH}$. Temperature was kept constant during storage, and thus could not explain changes in lipolysis rate. The $\mathrm{pH}$ was followed during the storage experiment and was found to decrease from 6.0 to 5.2 when storing at $20^{\circ} \mathrm{C}$. As in literature rather high $\mathrm{pH}$ optima, varying between 6.5 and 9.0, are reported for lipases in microalgae (Demir et al., 2010; Terasaki et al., 2002), this pH decrease could possibly affect the enzymatic reaction. Therefore, an additional experiment was conducted in which the $\mathrm{pH}$ was set at $4.0 \pm 0.1$ immediately after harvest to make the $\mathrm{pH}$ even more unfavorable for lipolytic enzymes. The $\mathrm{pH}$ was kept at this value during 2 weeks of storage at $4^{\circ} \mathrm{C}$. Figure 2 compares the obtained results with a sample in which the $\mathrm{pH}$ was not adapted. The FFA content in the start biomass was higher $(14.3 \pm 0.5 \%$ of total lipids) than in the previous experiment ( $7.5 \pm 0.3 \%$ of total lipids). This can be explained by the fact that different batches always vary in composition. In addition, the rapid increase of the FFA content during the first hours of wet storage causes a high variation in the beginning of the storage period. It can be observed that lipolysis was not inhibited by lowering the $\mathrm{pH}$. On the contrary, the process was found to start faster and reach the same end value as the control sample after 1 week of storage. Probably, the lower $\mathrm{pH}$ caused a more rapid rupture of the cell and consequently faster lipolysis reactions. From this additional experiment, it could be concluded that the level off of 

the FFA content in the lipid fraction was not caused by unfavorable conditions for hydrolytic enzymes.

Figure 2: Evolution of FFA content (\% of total lipids) during storage of wet microalgal paste of $T$-Isochrysis lutea at $4^{\circ} \mathrm{C}$, both without adapting the $\mathrm{pH}($ control, $\bullet$ ) and with holding the $\mathrm{pH}$ at a lower value $(\mathrm{pH} 4.0,0)$.

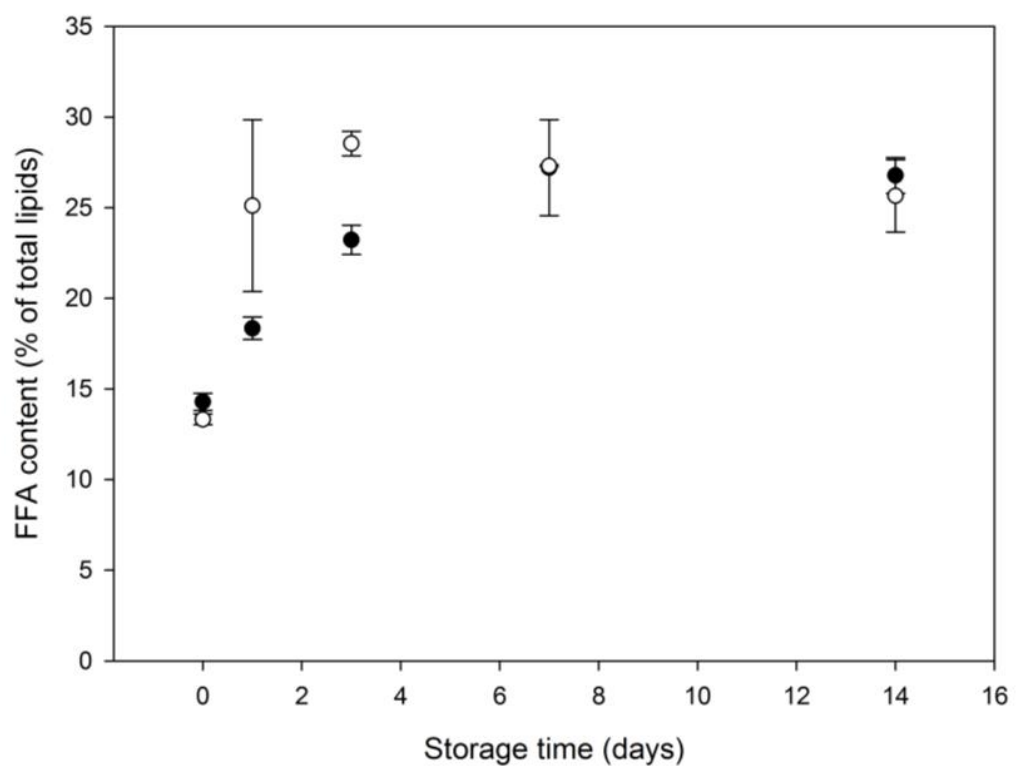

366

367 A second possible explanation for the stabilization of the FFA content is the lack of 368 substrate. Possibly, the lipase enzymes present in T-Isochrysis act specifically on some lipid classes, causing termination of the process when these specific lipid classes are exhausted. To investigate this hypothesis, a separation in lipid classes was conducted on

371 all collected samples. Figure 3 presents the evolution of all lipid classes during wet

372 storage of $T$-Isochrysis at $20^{\circ} \mathrm{C}$. During storage at $4^{\circ} \mathrm{C}$, almost the same trends were observed, although occurring at a lower rate, while at $-20^{\circ} \mathrm{C}$, no substantial changes were observed. This confirms the (from Figure 1) expected temperature dependency of the degradation reactions. 
Figure 3: Evolution of different lipid classes during 3 weeks of storage of wet biomass

377 (8\% dry matter) of T-Isochrysis lutea at $20^{\circ} \mathrm{C}$. Amounts are represented as relative 378 abundances (arbitrary units).
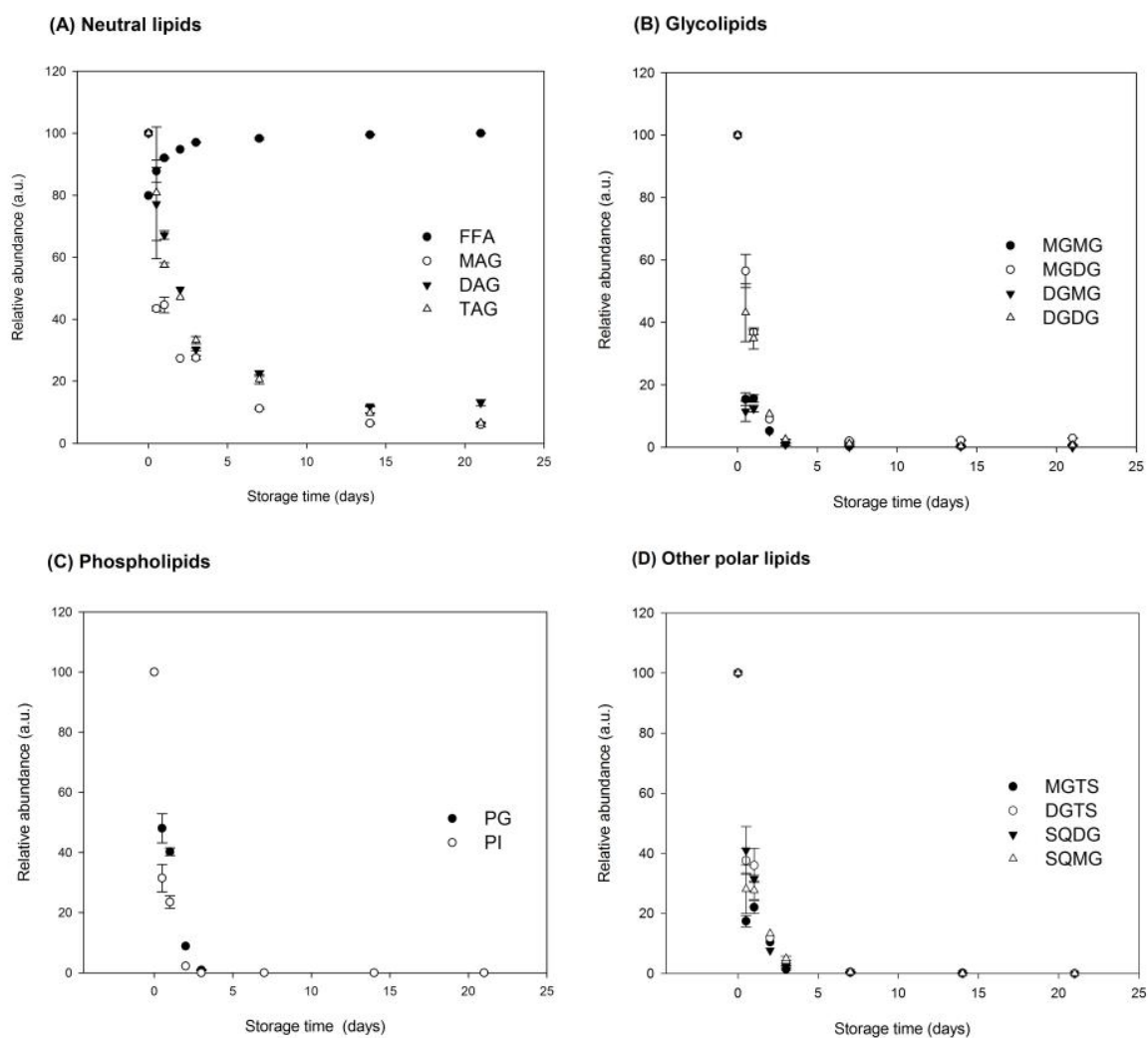

(E) Fatty acyl esters

(F) Overview of all lipid classes
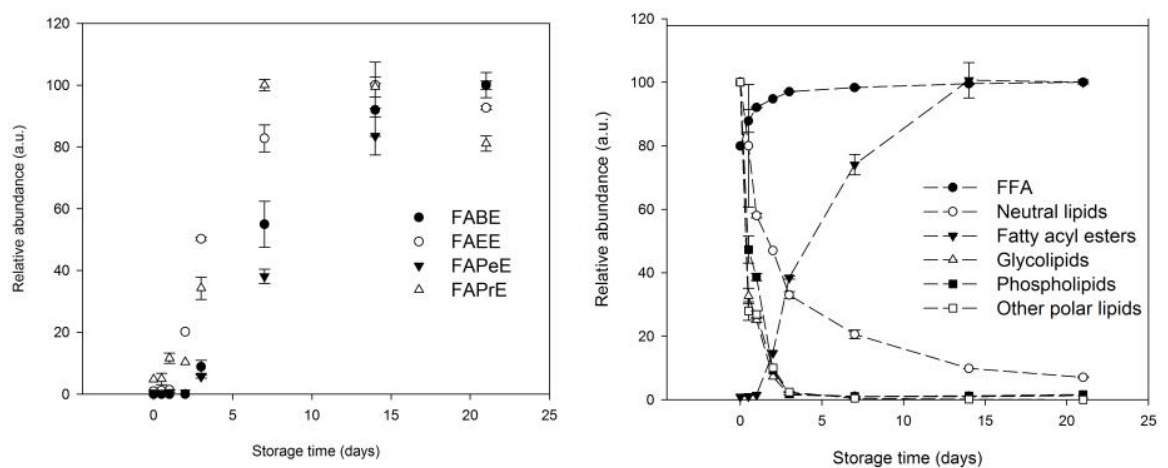

381 The neutral lipid class consisted mainly of FFA, TAG (triacylglycerols), DAG 382 (diacylglycerols) and MAG (monoacylglycerols), for which the evolution during storage 
at $20^{\circ} \mathrm{C}$ is presented in Figure $3 \mathrm{~A}$. The evolution of the FFA showed the same trend as was obtained previously by the method described in 2.3.2 (Figure 1). All other neutral lipids showed a decreasing trend during wet storage. TAG were thus converted to DAG, followed by conversion to MAG and eventually to glycerol, in each step accompanied by the release of FFA. This process started immediately after harvest. TAG, DAG as well as MAG followed the same evolution, decreasing to a value that is not equal to zero. However, because no response factors were available, the remaining percentage of these lipid classes in the lipid fraction after 3 weeks of storage could not be calculated.

In the glycolipid class (Figure 3B), the following compounds were found: MGMG (monogalactosyl monoacylglycerol), MGDG (monogalactosyl diacylglycerol), DGMG (digalactosyl monoacylglycerol) and DGDG (digalactosyl diacylglycerol). MGDG and DGDG can be converted to respectively MGMG and DGMG by release of FFA and can be further degraded to galactosylglycerols, also accompanied by the release of FFA. It can be observed from Figure $3 \mathrm{~B}$ that all glycolipids were degraded very rapidly during storage at $20^{\circ} \mathrm{C}$ and disappeared after only three days of wet storage. Phospholipids (mainly phosphatidylglycerol and phosphatidylinositol) were only found in very small amounts in the lipid samples, as peak areas in LC-MS analyses were very small. Nevertheless, a clear evolution could be observed during storage (Figure 3C), again being a very fast decrease during storage. The same observation could be made for the other polar lipids in the samples, which were DGTS (diacylglycerol-O-(N,N,N-trimethyl)homoserine), MGTS (monoacylglycerol-O-( $\mathrm{N}, \mathrm{N}, \mathrm{N}$-trimethyl)-homoserine), SQDG 
405 (sulfoquinovosyl diacylglycerol) and SQMG (sulfoquinovosyl monoacylglycerol). DGTS and SQDG are degraded to respectively MGTS and SQMG, which can then be further degraded by loss of the last fatty acyl chain, in each step accompanied by the release of a FFA. It could thus be concluded that all polar lipids were broken down very rapidly by a degradation process that started immediately after harvesting and which resulted in the absence of polar lipids after 3 days of wet storage at $20^{\circ} \mathrm{C}$. This is in contrast with the study of Chen et al. (2012) on wet storage of Scenedesmus sp., in which the phospholipid content remained constant during 4 days of storage at $4^{\circ} \mathrm{C}$.

A remarkable observation is the increasing amount of fatty acyl esters, mainly ethyl-, propyl-, butyl- and pentylesters present in the lipid fraction, as presented in Figure 3E. Fatty acyl esters were probably formed by an esterification reaction between free fatty acids, released during degradation of lipids, and alcohols. As storage was conducted in the dark and no oxygen supply was present, alcohols were possibly formed during dark fermentation reactions (Atteia et al., 2013). To confirm the presence of these alcohols, the volatile components of all wet biomass samples (before freeze drying) were analyzed by headspace-solid phase microextraction - gas chromatography - mass spectrometry (HS-SPME-GC-MS). Via this method, the presence of ethanol, propanol and pentanol could be confirmed and the amounts were found to increase during storage at $20^{\circ} \mathrm{C}$ and $4^{\circ} \mathrm{C}$. During storage at $-20^{\circ} \mathrm{C}$, none of these alcohols were found. The increasing amounts of ethanol even completely matched with the increasing amounts of the corresponding ester (Figure 4). These findings confirm the hypothesis that the 426 formation of fatty acyl esters is associated with the presence of alcohols. Possibly, the reaction between alcohols and free fatty acids is an enzymatic reaction catalyzed by the 
428 lipase enzymes, as external lipases are already used in several applications to convert 429 free fatty acids to fatty acyl esters, for example in enzymatic transesterification during 430 biodiesel production (Navarro Lopez et al., 2015).

431

432 Figure 4: Evolution of fatty acyl ethyl esters (FAEE), determined by UHPLC- amMS) 433 compared to the evolution of the corresponding ethanol, determined by HS-SPME-GC434 MS, during 3 weeks of storage of wet biomass (8\% dry matter) of T-Isochrysis lutea at $43520^{\circ} \mathrm{C}(\bullet), 4^{\circ} \mathrm{C}(0)$ and $-20^{\circ} \mathrm{C}(\nabla)$.
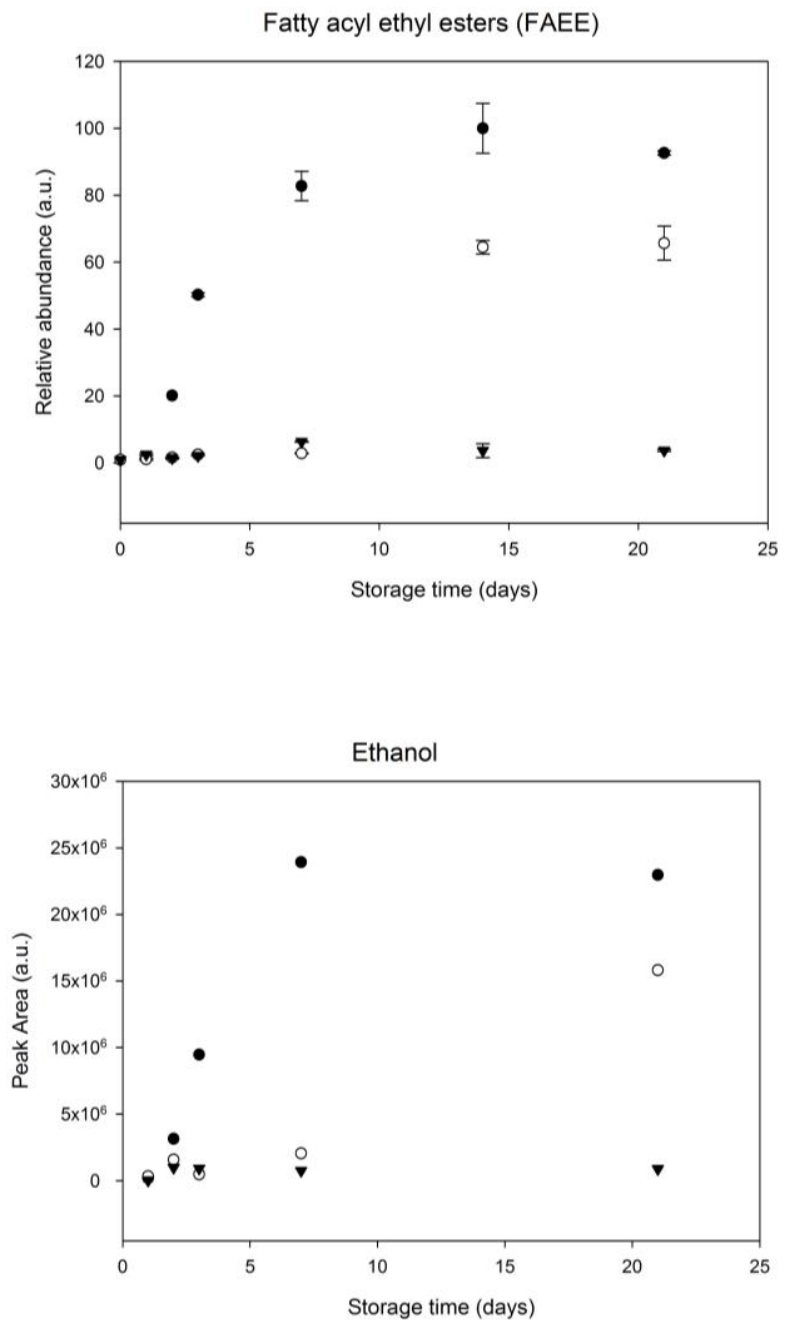
437

438

439

440

441

442

443

444

445

446

447

450

451

452

453

454

455

456

457

458

Figure $3 \mathrm{~F}$ presents an overview of the trends in the amounts of the different lipid classes.

For this figure, the different lipid compounds within one class are taken together, because they followed the same evolution, as could be seen in Figure 3A-E. In general, it can be seen that all lipid classes, and not one lipid class specifically, were degraded from the beginning of the storage experiment, immediately after harvest. This implies the presence of non-specific hydrolyzing enzymes, possibly rather esterases than lipases. The polar lipids seem to disappear faster than the neutral lipids, but this may be explained by the lower amounts of polar lipids present in the beginning of the storage experiment. After 7 days of storage at $20^{\circ} \mathrm{C}$, the FFA content started to level off, while the neutral lipids were not yet at the minimum value. It could thus be concluded that substrate limitation could not be the reason of the level off effect. It is hypothesized that the decline in the rate of FFA formation over time is due to a dynamic balance between hydrolysis of esterified fatty acids and re-esterification of free fatty acids with alcohols.

\subsubsection{Implications for lipid applications}

The results of this study will have important implications for the different applications of microalgal lipids. The fast increase in FFA during storage at $20^{\circ} \mathrm{C}$ and $4^{\circ} \mathrm{C}$ makes storage of wet microalgal paste of T-Isochrysis at $20^{\circ} \mathrm{C}$ or $4^{\circ} \mathrm{C}$ undesirable. Even short term storage at these temperatures will result in high amounts of FFA ( 7 to $30 \%$ of total lipids). To completely avoid lipolysis problems, wet biomass should be stored at $-20^{\circ} \mathrm{C}$ or further processed (dried) immediately. But even then, a high amount of FFA ( $7.5 \%$ of the lipids) is already present in T-Isochrysis due to hydrolysis processes going on during harvesting. This high percentage already exceeds the maximum value for biodiesel 
production (0.5\% FFA) (Navarro Lopez et al., 2015) and also the provided value for edible 460 oils (0.1\% FFA) (Belitz et al., 2009) and is consequently problematic for these applications. In current applications with high FFA oils, refining is conducted either by soap formation with alkali materials, or by a pretreatment with acid or alkali catalyzed transesterification processes, in order to strongly reduce the FFA percentage. However, this results in yield losses and much higher production costs (Chai et al., 2014) and

465 should thus better be avoided. Further research should reveal the microalgal species dependency of lipolysis processes and possible remediating actions to diminish lipolysis

467 during wet storage.

It was observed that FFA were formed by endogenous enzymes during and/or immediately after harvesting of T-Isochrysis lutea. This FFA content increased rapidly

471 during post-harvest wet storage at $20^{\circ} \mathrm{C}$ and $4^{\circ} \mathrm{C}$, while almost no lipolysis was observed at $-20^{\circ} \mathrm{C}$. However, the FFA content levelled off after several days of storage, probably

473 because FFA reacted with alcohols to form fatty acyl esters. It could be concluded that even short term wet storage of T-Isochrysis lutea biomass at $20^{\circ} \mathrm{C}$ or $4^{\circ} \mathrm{C}$ is detrimental

475 for lipid quality and should be avoided to have biomass of good quality for food and fuel applications. 
1. Atteia, A., van Lis, R., Tielens, A.G.M., Martin, W.F., 2013. Anaerobic energy metabolism in unicellular photosynthetic eukaryotes. Biochim. Biophys. Acta 1827, 210-223.

2. Aubourg, S.P., 2001. Fluorescence study of the pro-oxidant effect of free fatty acids on marine lipids. J. Sci. Food Agric. 81, 385-390.

3. Barka, F., Angstenberger, M., Ahrendt, T., Lorenzen, W., Bode, H.B., Büchel, C., 2016. Identification of a triacylglycerol lipase in the diatom Phaeodactylum tricornutum. Biochim. Biophys. Acta 1861, 239-248.

4. Belitz, H.-D., Grosch, W., Schieberle, P., 2009. Food Chemistry, $4^{\text {th }}$ revised and extended ed. Springer-Verlag, Berlin. 1070 p.

5. Berge, J.-P., Gouygou, J.-P., Dubacq, J.-P., Durand, P., 1995. Reassessment of lipid composition of the diatom Skeletonema costatum. Phytochem. 39(5) , 1017-1021.

6. Borowitzka, M.A., 2013. High-value products from microalgae-their development and commercialization. J. Appl. Phycol. 25, 743-756.

7. Calder, P.C., 2014. Very long chain omega-3(n-3) fatty acids and human health. Eur. J. Lipid Sci. Technol. 116, 1280-1300.

8. Chai, M., Tu, Q., Lu, M., Yang, J.Y., 2014. Esterification pretreatment of free fatty acid in biodiesel production, from laboratory to industry. Fuel Process. Tech. 125, 106-113.

9. Chen, L., Liu, T., Zhang, W., Chen, X., Wang, J., 2012. Biodiesel production from algae oil high in free fatty acids by two-step catalytic conversion. Biores. Technol. 111, 208-214. 10. Cho, S.H., Thompson, G.A., 1986. Properties of a fatty acyl hydrolase preferentially attacking monogalactosyldiacylglycerols in Dunaliella salina chloroplasts. Biochim. Biophys. Acta 878, 353-359. 
11. Cho, J.-Y., Choi, J.-S., Kong, I.-S., Park, S.-I., Kerr, R.G., Hong, Y.-K., 2002. A procedure for axenic isolation of the marine microalga Isochrysis galbana from heavily contaminated mass cultures. J. Appl. Phycol. 14, 385-390.

12. Cosse, A., Leblanc, C., Potin, P., 2008. Dynamic defense of marine macroalgae against pathogens: from early activated to gene-regulated responses. Adv. Bot. Res. 46, 222250.

13. Demir, B.S., Tükel, S.S., 2010. Purification and characterization of lipase from Spirulina platensis. J. Mol. Catal. B: Enzym. 64, 123-128.

14. Espinosa, E.P., Perrigault, M., Ward, E., Shumway, S.E., Allam, B., 2010. Microalgal cell surface carbohydrates as recognition sites for particle sorting in suspension-feeding bivalves. Biol. Bull. 218, 75-86.

15. Frankel, E.N., 2005. Lipid oxidation, second edition. The Oily Press, Bridgwater.

16. Godet, S., Loiseau, C., Pencreac'h, G., Ergan, F., Hérault, J., 2010. Isolation and sequence analysis of a cDNA encoding a novel putative esterase from the marine microalga Isochrysis galbana (Prymnesiophyceae, Haptophyta). J. Phycol. 46, 679-684.

17. Godet, S., Hérault, J., Pencreac'h, G., Ergan, F., Loiseau, C., 2012. Isolation and analyses of a gene from the marine microalga Isochrysis galbana that encodes a lipase-like protein. J Appl Phycol 24, 1547-1553.

18. Gordon, M.H., 2001. The development of oxidative rancidity in food. In "Antioxidants in food. Practical applications" (Pokorny, J., Yanishlieva, N., Gordon, M., Ed.), pp. 7-20, CRC Press, Boca Raton.

19. Guillard, R.R.L., Lorenzen, C.L., 1972. Yellow-green algae with chlorophyllide c. J. Phycol. 8, 1-14. 
20. Huerlimann, R., de Nys, R., Heimann, K., 2010. Growth, lipid content, productivity, and fatty acid composition of tropical microalgae for scale-up production. Biotechn. and Bioeng. 107 (2), 245- 257.

21. Kangani C.O., Kelley D.E., DeLany J.P., 2008. New method for GC/ FID and GC-C-IRMS analysis of plasma free fatty acid concentration and isotopic enrichment. J Chrom B 873, 95-101.

22. Kerviel, V., Hérault, J., Dumur, J., Ergan, F., Poisson, L., Loiseau, C., 2014. Cloning and expression of a gene from Isochrysis galbana modifying fatty acid profiles in Escherichia coli. J Appl Phycol 26, 2109-2115.

23. Koller, M., Muhr, A., Braunegg, G., 2014. Microalgae as versatile cellular factories for valued products. Algal Research 6, 52-63.

24. Li, L., Cui, J., Liu, Q., Ding, Y., Liu, J., 2015. Screening and phylogenetic analysis of lipidrich microalgae. Algal Research 11, 381-386.

25. Mata, T.M., Martins, A.A., Caetano, N.S., 2010. Microalgae for biodiesel production and other applications : a review. Renew Sust Energy Reviews 14, 217-232.

26. Navarro López, E., Robles Medina, A., González Moreno, P.A., Jiménez Callejón, M.J., Esteban Cerdán, L., Martin Valverde, L., Castillo López, B. and Molina Grima, E., 2015. Enzymatic production of biodiesel from Nannochloropsis gaditana lipids: Influence of operational variables and polar lipid content. Biores. Techn. 187, 346-353.

27. Pohnert, G., 2002. Phospholipase A2 activity triggers the wound-activated chemical defense in the diatom Thalassiosira rotula. Plant Physiol. 129, 103-111.

28. Ryckebosch, E., Muylaert, K., Eeckhout, M., Ruyssen, T., Foubert, I., 2011a. Influence of drying and storage on lipid and carotenoid stability of the microalga Phaeodactylum tricornutum. J. Agric. Food Chem. 59, 11063-11069. 
29. Ryckebosch, E., Muylaert, K., Foubert, I., 2011b. Optimization of an analytical procedure for extraction of lipids from microalgae. J. Am. Oil Chem. Soc. 89, 189-198.

30. Slegers, P.M., Koetzier, B.J., Fasaei, F., Wijffels, R.H., van Straten, G., van Boxtel, A.J.B., 2014. A model-based combinatorial optimisation approach for energy-efficient processing of microalgae. Algal Research 5, 140-157.

31. Spolaore, P., Joannis-Cassan, C., Duran, E., Isambert, A., 2006. Commercial applications of microalgae. J. Biosci. Bioeng. 101(2), 87-96.

32. Tanzi, C.D., Vian, M.A., Chemat, F., 2013. New procedure for extraction of algal lipids from wet biomass: a green clean and scalable process. Biores.Techn. 134, 271-275.

33. Terasaki, M., Itabashi, Y., 2002. Free fatty acid level and galactolipase activity in a red tide flagellate Chatonella marina (Raphidophyceae). J. Oleo Sci 51 (3), 213-218.

34. Vandamme, J., Nikiforov, A., Dujardin, K., Leys, C., De Cooman, L., Van Durme, J., 2015. Critical evaluation of non-thermal plasma as an innovative accelerated lipid oxidation technique in fish oil. Food Res. Int. 72, 115-125.

35. Wahlen, B.D., Willes, R.M., Seefeldt, L.C., 2011. Biodiesel production by simultaneous extraction and conversion of total lipids from microalgae, cyanobacteria, and wild mixed-cultures. Biores. Techn. 102, 2724-2730.

36. Xu, L., Brilman, D.W.F., Withag, J.A.M., Bremb, G., Kersten, S., 2011. Assessment of a dry and a wet route for the production of biofuels from microalgae: Energy balance analysis. Biores. Techn. 102, 5113-5122 C.

37. Zhu, C.J., Lee, Y.K., 1997. Determination of biomass dry weight of marine microalgae. J. Appl. Phycol. 9, 189-194.

38. Zhu, C.J., Lee, Y.K., Chao, T.M., 1997. Effects of temperature and growth phase on lipid and biochemical composition of Isochrysis galbana TK1. J. Appl. Phycol. 9, 451-457. 
Figure 1: Evolution of the FFA content (\% of total lipids) during 3 weeks of storage of wet biomass ( $8 \%$ dry matter) of T-Isochrysis lutea at $20^{\circ} \mathrm{C}(\bullet), 4^{\circ} \mathrm{C}(0)$ and $-20^{\circ} \mathrm{C}(\nabla)$.

Figure 2: Evolution of FFA content (\% of total lipids) during storage of wet microalgal paste of $T$-Isochrysis lutea at $4^{\circ} \mathrm{C}$, both without adapting the $\mathrm{pH}($ control, $\bullet$ ) and with holding the $\mathrm{pH}$ at a lower value $(\mathrm{pH} 4,0)$.

Figure 3: Evolution of different lipid classes during 3 weeks of storage of wet biomass (8\% dry matter) of $T$-Isochrysis lutea at $4^{\circ} \mathrm{C}$. Amounts are represented as relative abundances (arbitrary units).

Figure 4: Evolution of fatty acyl ethyl esters (FAEE), determined by UHPLC- amMS) compared to the evolution of the corresponding ethanol, determined by HS-SPME-GCMS, during 3 weeks of storage of wet biomass ( $8 \%$ dry matter) of T-Isochrysis lutea at $20^{\circ} \mathrm{C}(\bullet), 4^{\circ} \mathrm{C}(0)$ and $-20^{\circ} \mathrm{C}(\nabla)$

\section{Caption of supplemental material}

Appendix 1: Spectral and chromatographic data used for tentative identification of lipids in the T-Isochrysis lutea samples. 